\title{
The Association Between Deficiency of Nutrient Intake on Resting Metabolic Rate in Overweight and Obese Women: a Cross-sectional Study
}

\author{
Seyedeh Forough Sajjadi \\ Tehran University of Medical Sciences \\ Atieh Mirzababaei \\ Tehran University of Medical Sciences \\ Afsoun Abdollahi \\ Purdue University \\ Farideh Shiraseb \\ Tehran University of Medical Sciences \\ Khadijeh Mirzaei ( $\nabla$ mirzaei_kh@tums.ac.ir) \\ Tehran University of Medical Sciences https://orcid.org/0000-0002-7554-8551
}

\section{Research note}

Keywords: Resting metabolic rate, fat-free mass, obesity, overweight, the double burden of malnutrition, Nutrient Adequacy Ratio

Posted Date: January 15th, 2021

DOI: https://doi.org/10.21203/rs.3.rs-143488/v1

License: (c) (1) This work is licensed under a Creative Commons Attribution 4.0 International License. Read Full License 


\section{Abstract}

Objective: The double burden of malnutrition is an emerging public health concern nowadays which a correlation with Obesity. This study aimed to examine the relationship between resting metabolic rate (RMR) and dietary intake of zinc, vitamin C, and riboflavin in overweight and obese women.

Results: the RMR/FFM showed a significant association with riboflavin ( $\beta=1.59 ; 95 \% \mathrm{Cl}$ : 1.04-23.26, $P=0.04)$ and zinc $(\beta=0.78 ; 95 \% \mathrm{Cl}$ : $1.04-4.61, P=0.03)$ in the crude model. Moreover, differences in vitamin $C$ and RMR/FFM was marginal significant $(\beta=0.75 ; 95 \%$ Cl: 0.95-4.77, $P=0.06)$. After adjusting for confounders the riboflavin association change to marginal significance $(\beta=1.52 ; 95 \% \mathrm{Cl}: 0.91-23.04, P=0.06)$. After controlling for potential confounders, the associations change between zinc and RMR/FFM ( $\beta=0.66$; $95 \% \mathrm{Cl}$ : 0.78-4.86, $P=0.15)$ and between RMR/FFM and vitamin $C(\beta=0.48 ; 95 \%$ Cl: $0.66-3.96$, $\mathrm{P}=0.28$ ). Our study showed a significant association between dietary intake of zinc, riboflavin, and vitamin $\mathrm{C}$ and change in RMR/FFM in overweight and obese women.

\section{Introduction}

Obesity rates are growing globally (1). More than $26 \%$ of the Iranian adult community is currently obese (2) Females were much more affected than males $(3,4)$. Obesity and its associated metabolic disorders develop when energy intake is more than energy expenditure; this can be caused by diminished physical activity, the disability of the central nervous system to down-regulate the ingestion of high-calorie foods, or appetite (5). Although various factors contribute to the etiology of obesity, sedentary lifestyles, and unhealthy eating habits are among the principal contributors to the world obesity epidemic (6). $60 \_75 \%$ of total energy expenditure is correlated with resting metabolic rate (RMR), which is an important part of daily energy consumption (7). weight gaining and obesity may be associated with low RMR(8).

Diet quality can be evaluated to better understand overall eating patterns (9). Poor diet quality is a significant factor in the development of many chronic diseases, including obesity (10). Investigations revealed, however, intake of vegetables and fruit is associated with a lower risk of obesity (11), inappropriate food behavior contributes to obesity and contributes to vitamin deficiency. Studies revealed that most vitamins are inadequate in obese individuals (12). The double burden of malnutrition (DBM) is an emerging public health concern nowadays that happens as an inevitable consequence of nutritional transition (13). The coexistence of overnutrition and undernutrition is often referred to as the DBM (14). Nutrient Adequacy Ratio (NAR) and mean adequacy ratio (MAR), known as healthier diet quality indices. Higher scores in diet quality inversely connected with body mass index (BMI), and obesity (15). Similarly, zinc and vitamin $C$ are closely related to adiposity $(16,17)$. In particular, some diet with a high score of diet quality like the Mediterranean dietary pattern has been reported to be inversely connected with BMI, and waist circumference (18).

To the best of our knowledge, this is the first study to investigate the relationship between deficiency of nutrient intakes such as zinc, vitamin C, and riboflavin and RMR in the adult women population. Accordingly, this study was performed to examine the NAR with RMR/FFM among a group of Iranian adult women.

\section{Materials And Methods Study population}

This cross-sectional research was performed on 293 adult women aged between 18 and 48 years old who were selected by a multistage cluster random sampling method that had been referred to health centers in Tehran recruited. Participants were enrolled in the study according to inclusion and exclusion criteria. Inclusion criteria were: general health, overweight and obese women with BMI in the range of $25-40 \mathrm{~kg} / \mathrm{m}^{2}$. The exclusion criteria were as follows: regular use of medicine, history of hypertension, cardiovascular diseases, and other chronic diseases, alcohol consumption, smoking, pregnancy, lactation period, and menopause. Furthermore, those who had been following an arbitrary special dietary regimen, and also those with any significant body weight fluctuations over the past 1 year and energy intakes lower than $800 \mathrm{kcal} / \mathrm{d}$ or higher than $4200 \mathrm{kcal} / \mathrm{d}$ were excluded.

\section{Energy Expenditure Measurements}

RMR was measured by indirect calorimetry (spirometer METALYZERR 3B-R3, Cortex Biophysik GmbH, Leipzig, Germany). According to the manufacturer's instructions, gas ventilation and exchange is calibrated before each test. RMR is evaluated by measuring the amount of $\mathrm{O}_{2}$ consumed and $\mathrm{CO}_{2}$ produced. The RMR was assessed in the morning, after a comfortable night's sleep, and following a 10-12 hour fast. Participants were asked to avoid caffeine or alcohol consumption and severe exercise for a day before RMR measurements. After reclining in a steady-state and a supine position in a quiet room, the RMR was measured for 30 minutes. The respiratory exchange ratio and oxygen uptake $\left(\mathrm{VO}_{2}\right)$ were analyzed within the middle 20 min of the resting period. Predictive RMR was determined using the Harris-Benedict equation, which considers the weight, height, and age of participants.

\section{Body Composition Measurement}

Body composition, including weight, BMI, fat mass, and fat-free mass (FFM) were acquired using a multi-frequency bioelectrical impedance analyzer InBody 770 scanner (Inbody Co., Seoul, Korea According to the manufacturer's instructions, participants removed their shoes, coats, and sweaters, and stood on the balance scale in bare feet, and grasped the handles of the machine. 


\section{Biochemical Assessment and Hormonal Assay}

Metabolic health was assessed using the metabolic parameters that measured following standard chemical procedures. A 12-hour fasting venous blood sample was used to measure all biochemical markers. Serum glucose was evaluated by a colorimetric method based on the GOD-PAP method. Serum insulin concentrations were analyzed by enzyme-linked immunosorbent assay (ELISA) method (Human insulin ELISA kit, Monobind Inc., Lake Forest, USA).

\section{HOMA and QUICKI Calculations}

Insulin resistance was estimated by homeostasis model assessment (HOMA). The HOMA was calculated according to the following equation: HOMA = [Fasting Plasma Glucose (mmol/L) × Fasting Plasma Insulin (mIU/L)]/22.5 (19). Insulin sensitivity quantitative insulin sensitivity check index (ISQUICKI) was assessed by: ISQUICKI = 1/[log (fasting insulin) + log (fasting glucose) (20).

\section{Dietary intake assessment}

Dietary intake data of the past year were obtained using a validated semi-quantitative food-frequency questionnaire (FFQ)(21), comprised of 168-item a trained nutritionist administered these FFQ. The FFQ consisted of a list of foods with standard serving sizes. Participants were asked to report their frequency and amount of each food item consumed during the previous year. Portion sizes of the consumed foods were converted to grams using household measurements(22). Nutritionist IV computer software was used for the nutrient analysis of the diets. The database of this software was modified for Iranian foods.

\section{Nutrient Adequacy Ratios (NAR)}

For calculating the NAR, the ratio of daily individual intakes to the standard recommended amounts for the subject's sex and age category was used. The standard recommended amounts are based on RDA (Recommended Daily Allowances) (23). We calculated the NAR for three key nutrients, including zinc, vitamin $\mathrm{C}$, and riboflavin according to the above-mentioned method. The prevalence of nutrient deficiency was estimated using NAR. NAR lower than one is considered as a deficiency.

\section{Assessment of other covariates}

International Physical Activity Questionnaire (IPAQ, short form) were obtained by using an interview-based questionnaire from all participants about all the vigorous and moderate elements over the last 7 days, considering the time spent on these activities for height measurements, subjects were in a standing position without shoes, in contact with the wall with their head, shoulders, heels, and hips, and their height was recorded to the nearest $0.1 \mathrm{~cm}$.

\section{Statistical analysis}

All statistical analysis was performed using the IBM SPSS software version 22.0 (SPSS, Chicago, IL, USA), and p-values less than 0.05 were considered statistically significant. Normal distribution of data was checked by the Kolmogorov-Smirnov test. An independent sample t-test was used for assessed differences between groups with the low and standard intake of nutrients. RMR/FFM was analyzed after adjusting for FFM. The differences between RMR/FFM groups and dietary intake of nutrients were assessed by the Binary logistic regression were performed to adjust for confounders effects such as age, energy intake, and physical activity (METs/d). Results were presented as odds ratios (ORs) and 95\% confidence intervals (Cls) compared with the RMR groups.

\section{Results}

\section{Study population characteristics}

A total of 293 healthy overweight and obese women were enrolled. The mean age, height, weight, and BMI of the study participants were 36.39 years (SD = 8.71), $161.84 \mathrm{~cm}(\mathrm{SD}=5.85), 80.22 \mathrm{~kg}(\mathrm{SD}=11.28)$, and $30.77 \mathrm{~kg} / \mathrm{m}^{2}(\mathrm{SD}=3.79)$, respectively (Table 1$)$ the mean body composition, RMR components, biochemical and anthropometric characteristics of subjects are shown in table 1. 
Table 1

Study of population characteristics

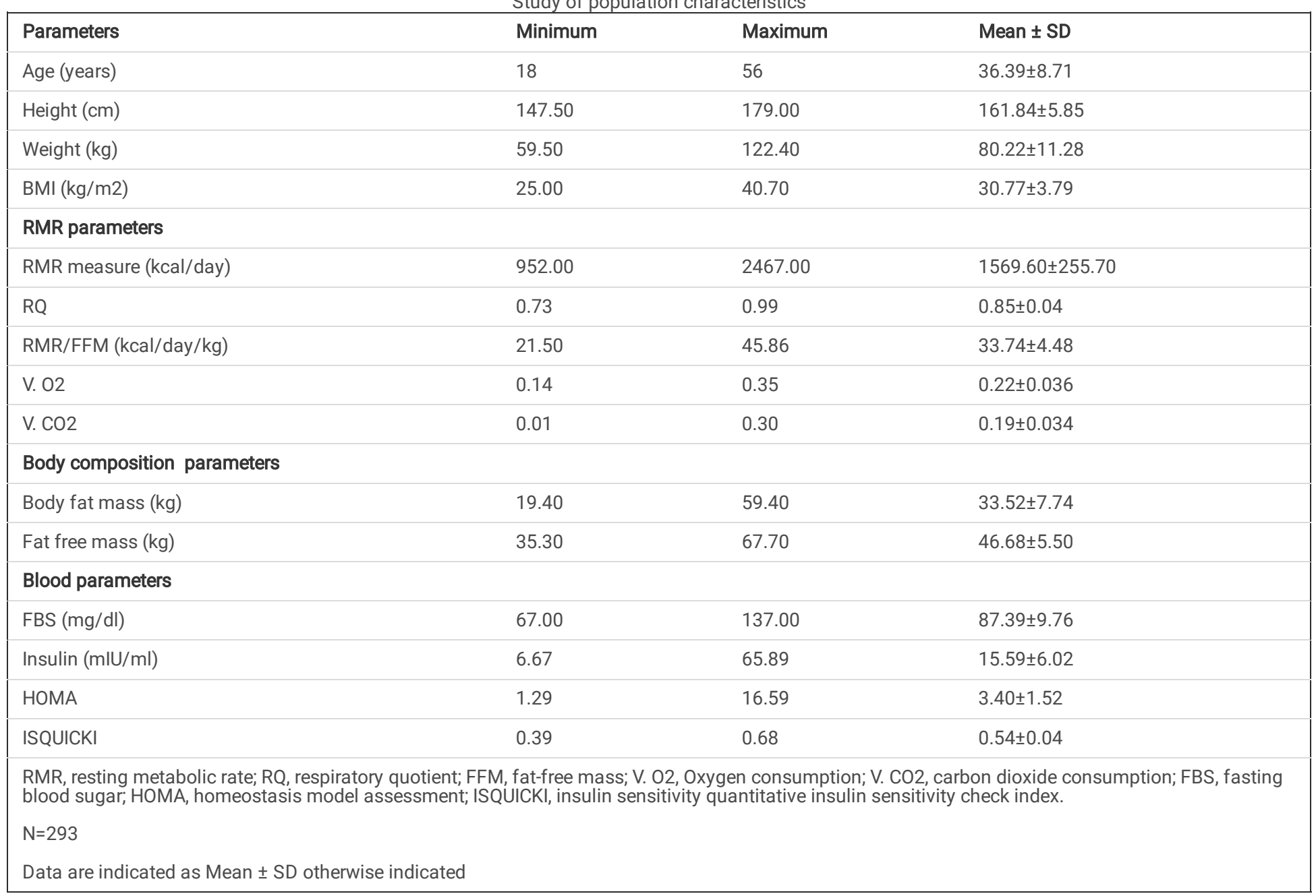

\section{Participant's characteristics between standard and deficiency of daily nutrient intakes}

Dietary intake of three nutrients including riboflavin, vitamin C, and zinc were categorized based on nutrient adequacy ratios (NAR) and divided into two groups, standard and deficiency (Table 2). The RMR indicated a significant association with zinc $(P=0.001)$, which demonstrates people who consume higher zinc had higher RMR. Moreover, other factors like RMR/FFM $(P=0.06), V . O_{2}(P=0.001), V . C O_{2}(P=0.007)$, body fat mass $(P=0.02), F F M(P=0.006)$, height $(P=0.005)$, and weight $(P=0.006)$ had a significant relationship with zinc. Besides, riboflavin had a significant association with body fat mass $(P=$ 0.05), however, there were showed no relationship between vitamin $C$ and participant characteristics $(P>0.05)$. 
Table 2

Participants' Characteristics between Standard and Deficiency of Daily Nutrient Intakes

\begin{tabular}{|c|c|c|c|c|c|c|c|c|c|}
\hline \multirow{5}{*}{ Parameters } & \multicolumn{8}{|c|}{ Nutrient } & \\
\hline & \multicolumn{2}{|c|}{ Vitamin c } & \multicolumn{3}{|c|}{ zinc } & \multicolumn{3}{|c|}{ Riboflavin } & \multirow{4}{*}{$\begin{array}{l}\mathrm{P} \text { - } \\
\text { value }\end{array}$} \\
\hline & NAR $<1$ & $N A R \geq 1$ & \multirow{3}{*}{$\begin{array}{l}P \text { - } \\
\text { value }\end{array}$} & NAR $<1$ & $N A R \geq 1$ & \multirow{3}{*}{$\begin{array}{l}\mathrm{P}- \\
\text { value }\end{array}$} & NAR $<1$ & $N A R \geq 1$ & \\
\hline & $n=30$ & $n=250$ & & $n=36$ & $n=244$ & & $n=11$ & $n=269$ & \\
\hline & $10.2 \%$ & $85.3 \%$ & & $12.3 \%$ & $83.3 \%$ & & $3.8 \%$ & $91.8 \%$ & \\
\hline Age (years) & $34.90 \pm 8.62$ & $63.60 \pm 8.53$ & 0.30 & $38.05 \pm 9.13$ & $36.18 \pm 8.44$ & 0.22 & $31.63 \pm 8.41$ & $36.62 \pm 8.50$ & 0.08 \\
\hline Height (cm) & $161.63 \pm 6.27$ & $161.32 \pm 5.82$ & 0.78 & $158.78 \pm 6.33$ & $161.74 \pm 5.70$ & 0.005 & $160.27 \pm 8.16$ & $161.40 \pm 5.76$ & 0.53 \\
\hline Weight (kg) & $77.54 \pm 9.28$ & $80.32 \pm 11.13$ & 0.19 & $75.35 \pm 8.78$ & $80.71 \pm 11.10$ & 0.006 & $75.61 \pm 14.41$ & $80.20 \pm 10.80$ & 0.17 \\
\hline BMI $\left(\mathrm{kg} / \mathrm{m}^{2}\right)$ & $29.78 \pm 3.29$ & $30.87 \pm 3.78$ & 0.13 & $29.91 \pm 3.40$ & $30.88 \pm 3.78$ & 0.15 & $29.30 \pm 4.03$ & $30.81 \pm 3.72$ & 0.19 \\
\hline \multicolumn{10}{|c|}{ RMR parameters } \\
\hline $\begin{array}{l}\text { RMR } \\
\text { measure } \\
\text { (kcal/day) }\end{array}$ & $1500.2 \pm 307.28$ & $1580.2 \pm 247.49$ & 0.17 & $1437.5 \pm 288.33$ & $1591.7 \pm 244.25$ & 0.001 & $1450.6 \pm 301.44$ & $1576.5 \pm 252.59$ & 0.10 \\
\hline RQ & $0.86 \pm 0.03$ & $0.85 \pm 0.04$ & 0.16 & $0.86 \pm 0.042$ & $0.85 \pm 0.041$ & 0.39 & $0.858 \pm 0.03$ & $0.854 \pm 0.04$ & \\
\hline $\begin{array}{l}\text { RMR/FFM } \\
\text { (kcal/day/kg) }\end{array}$ & $00.04 \pm 5.60$ & $33.92 \pm 4.36$ & 0.32 & $32.50 \pm 5.10$ & $34.02 \pm 4.39$ & 0.06 & $31.79 \pm 2.93$ & $33.91 \pm 4.54$ & 0.12 \\
\hline V. $\mathrm{O}_{2}$ & $0.21 \pm 0.04$ & $0.22 \pm 0.03$ & 0.13 & $0.20 \pm 0.04$ & $0.22 \pm 0.03$ & 0.001 & $0.20 \pm 0.04$ & $0.22 \pm 0.03$ & 0.13 \\
\hline V. $\mathrm{CO}_{2}$ & $0.18 \pm 0.04$ & $0.19 \pm 0.03$ & 0.22 & $0.17 \pm 0.04$ & $0.19 \pm 0.03$ & 0.007 & $0.17 \pm 0.04$ & $0.19 \pm 0.03$ & 0.16 \\
\hline \multicolumn{10}{|c|}{ Body composition parameters } \\
\hline $\begin{array}{l}\text { Body fat } \\
\text { mass (kg) }\end{array}$ & $31.80 \pm 6.66$ & $33.65 \pm 7.77$ & 0.21 & $30.79 \pm 6.66$ & $33.84 \pm 7.74$ & 0.02 & $29.15 \pm 7.10$ & $33.63 \pm 7.66$ & 0.05 \\
\hline $\begin{array}{l}\text { Fat free mass } \\
(\mathrm{kg})\end{array}$ & $45.63 \pm 5.26$ & $46.76 \pm 5.44$ & 0.28 & $44.27 \pm 4.74$ & $46.98 \pm 5.44$ & 0.006 & $45.55 \pm 7.70$ & $46.69 \pm 5.33$ & 0.49 \\
\hline \multicolumn{10}{|c|}{ Blood parameters } \\
\hline $\mathrm{FBS}(\mathrm{mg} / \mathrm{dl})$ & $86.50 \pm 10.59$ & $87.51 \pm 9.64$ & 0.60 & $87.93 \pm 11.62$ & $87.30 \pm 9.34$ & 0.73 & $83.30 \pm 7.33$ & $87.57 \pm 9.81$ & 0.17 \\
\hline $\begin{array}{l}\text { Insulin } \\
(\mathrm{mlU} / \mathrm{ml})\end{array}$ & $14.75 \pm 4.77$ & $15.70 \pm 6.30$ & 0.44 & $15.37 \pm 4.15$ & $15.62 \pm 6.41$ & 0.83 & $18.28 \pm 10.03$ & $15.47 \pm 5.93$ & 0.40 \\
\hline HOMA & $3.17 \pm 1.17$ & $3.42 \pm 1.59$ & 0.41 & $3.35 \pm 1.05$ & $3.40 \pm 1.61$ & 0.84 & $3.81 \pm 2.33$ & $3.38 \pm 1.50$ & 0.38 \\
\hline ISQUICKI & $0.55 \pm 0.045$ & $0.54 \pm 0.049$ & 0.49 & $0.540 \pm 0.03$ & $0.545 \pm 0.05$ & 0.58 & $0.53 \pm 0.05$ & $0.54 \pm 0.04$ & 0.70 \\
\hline \multicolumn{10}{|c|}{$\begin{array}{l}\text { RMR, resting metabolic rate; RQ, respiratory quotient; FFM, fat-free mass; } \mathrm{V} . \mathrm{O}_{2}, \text { Oxygen consumption; } \mathrm{V} . \mathrm{CO}_{2} \text {, carbon dioxide consumption; FBS, fasting } \\
\text { blood sugar; HOMA, homeostasis model assessment; ISQUICKI, insulin sensitivity quantitative insulin sensitivity check index. }\end{array}$} \\
\hline \multicolumn{10}{|l|}{$N=293$} \\
\hline \multicolumn{10}{|c|}{ Data are indicated as Mean \pm SD otherwise indicated } \\
\hline \multicolumn{10}{|c|}{ P-values are from independent sample t-test } \\
\hline
\end{tabular}

\section{Association of riboflavin, vitamin $\mathrm{C}$, and zinc with RMR/FFM among obese women}

Table 3 shows multivariate-adjusted models for the prevalence of higher RMR/FFM across the median dietary intake of riboflavin, vitamin C, and zinc. The RMR/FFM showed a significant association with riboflavin, vitamin $\mathrm{C}$, and zinc in the crude model. For riboflavin, in the crude model before adjustment for the confounders, showed a statistically significant relationship ( $\beta=1.59 ; 95 \% \mathrm{Cl}$ : 1.04-23.26, $\mathrm{P}=0.04)$. After controlling for the potential confounders, the association change to marginal significance $(\beta=1.52 ; 95 \% \mathrm{Cl}$ : 0.91-23.04, $\mathrm{P}=0.06)$. Moreover, differences in vitamin $\mathrm{C}$ and $\mathrm{RMR} / \mathrm{FFM}$ was marginal significant $(\beta=0.75 ; 95 \% \mathrm{Cl}: 0.95-4.77, P=0.06)$. But after controlling for the potential confounders, the association disappeared $(P=0.28)$. Differences in zinc and RMR/FFM were also significant in the crude model $(\beta=0.78 ; 95 \% \mathrm{Cl}: 1.04-4.61, P=0.03)$, but after adjustment for the potential confounders, the association disappeared $(\mathrm{P}=0.15)$. 
Table 3

Association of riboflavin, vitamin $\mathrm{C}$ and zinc and RMR/FFM among obese women

\begin{tabular}{|c|c|c|c|c|}
\hline RMR/FFM & & $\boldsymbol{\beta}$ & OR $(95 \% \mathrm{Cl})$ & P-value \\
\hline Crude Model & \multirow{4}{*}{ Riboflavin } & 1.59 & $4.93(1.04-23.26)$ & 0.04 \\
\hline Model1 a & & 1.75 & $5.80(1.21-27.77)$ & 0.02 \\
\hline Model $2^{b}$ & & 1.71 & $5.55(1.11-27.59)$ & 0.03 \\
\hline Model $3^{c}$ & & 1.52 & $4.58(0.91-23.04)$ & 0.06 \\
\hline Crude Model & \multirow{4}{*}{ Vitamin C } & 0.75 & $2.13(0.95-4.77)$ & 0.06 \\
\hline Model1 ${ }^{a}$ & & 0.82 & $2.27(1.01-5.13)$ & 0.04 \\
\hline Model2 ${ }^{b}$ & & 0.79 & $2.20(0.93-5.19)$ & 0.07 \\
\hline Model3 ${ }^{c}$ & & 0.48 & $1.62(0.66-3.96)$ & 0.28 \\
\hline Crude Model & \multirow{4}{*}{ Zinc } & 0.78 & $2.19(1.04-4.61)$ & 0.03 \\
\hline Model1 ${ }^{a}$ & & 0.71 & $2.04(0.96-4.33)$ & 0.06 \\
\hline Model2 ${ }^{b}$ & & 0.71 & $2.04(0.87-4.76)$ & 0.09 \\
\hline Model3 ${ }^{c}$ & & 0.66 & $1.95(0.78-4.86)$ & 0.15 \\
\hline
\end{tabular}

\section{Discussion}

The results of this study showed a significant association between vitamin C, zinc, and riboflavin intake and the RMR/FFM. RMR was distinct in standard or deficiency consumption of vitamin $\mathrm{C}$, zinc, and riboflavin.

The findings of the current study indicate that the amount of zinc consumed has been associated with RMR which higher intakes of zinc enhance RMR. This finding is in the same line with a study by Maxwell which demonstrates that zinc is an essential factor in several enzymes, involved with energy metabolisms such as pyruvate carboxylase, lactate dehydrogenase, carbonic anhydrase, and aldolase (24). Some studies state that zinc is connected to obesity (25). Zinc deficiency may increase fat deposition and decrease lean mass accrual (26). The association between adiposity and zinc status may be attributed to the correlation between zinc metabolism and leptin (26). Moreover, zinc has different functions in the metabolism of energy and works as a component of several enzymes crucial to the metabolism of carbohydrates, proteins, and lipids and metabolism of hormones that take part in the progress of obesity, especially insulin, and seems to be connected with the mechanisms of insulin resistance usually present among obese people (11, 27, 28). Previous investigations recommend a negative association between RMR and insulin resistance $(29,30)$. Subjects with obesity and impaired glucose tolerance showed higher RMR levels than those with obesity and normal glucose tolerance (31).

This study found a significant association between vitamin C and RMR. It showed women with a higher intake of vitamin C had higher RMR. This result is in line with previous studies which showed that the increase in blood vitamin C concentrations associated with the change in RMR/FFM (32). In contrast, some other studies have shown that vitamin $\mathrm{C}$ administration significantly decreased RMR (33). A probable mechanism could be ascorbic acid modulation on lipolysis in the interior of adipocytes and inflammatory response (34). Vitamin C, an antioxidant, regulates glucocorticoid metabolism, and gene expression involved in adipogenesis (35). Ascorbic acid decreased weight gain and adipose tissue correlated with low expression of genes involved in adipogenesis, adipocyte differentiation, and metabolism of glucocorticoids (12). In an in-vitro assay, it was perceived that vitamin $\mathrm{C}$ inhibited glucose uptake and lactate production, and decreased glycerol release, and caused a consistent reduction of leptin secretion in a dose-dependent manner. (12).

In this study, we also found that women who consumed higher riboflavin were more likely to have higher RMR. Considering the dietary restrictions on food intake or common dietary mistakes perceived among obese people, changes in the micronutrient intake leading to their deficiency are possible. Suitable riboflavin content is necessary to perform the effector function of macrophages with inhibition proliferation, intensification of apoptosis incidence, and also the reduction in phagocytosis efficiency [9]. Furthermore, resting reactive oxygen species production was raised while respiratory burs, a key ingredient of intracellular killing, were destroyed. Considering the significant function of adipocytes in the creation of obesity-related chronic inflammation to be justifiable to verify the influence of riboflavin deficiency on adipocytes function in the context of pro-inflammatory activation (36).

\section{Conclusions}

In conclusion, we could find a significant association between dietary intake of zinc, riboflavin, and vitamin C and change in RMR/FFM in overweight and obese women, although after controlling for ranges of potential confounding factors the meaningful decreased. 


\section{Limitation}

The major limitation of this study was the participants in the same-sex sample that it is not possible to generalize the results to men population. Because of the study type, cross-sectional study, we could not determine the causality Another limitation for assessing dietary intakes from FFQ is misclassification. Albeit we controlled for the effect of the potential confounder by the statistical methods, because of unknown confounder cannot be excluded residual confounding will affect.

\section{Abbreviations}

RMR: Resting Metabolic Rate; DBM: Double Burden of Malnutrition; NAR: Nutrient Adequacy Ratio; MAR: Mean Adequacy Ratio; BMI: Body Mass Index; FFM: Fat-Free Mass; ELISA: Enzyme-Linked Immuno-Sorbent Assay; HOMA: homeostasis model assessment; ISQUICKI: Insulin Sensitivity Quantitative Insulin Sensitivity Check Index; FFQ: Food Frequency Questionnaire; RDA: Recommended Daily Allowances; IPAQ: International Physical Activity Questionnaire; RQ: Respiratory Quotient; FBS: Fasting Blood Sugar.

\section{Declarations}

\section{Ethics approval and consent to participate}

All procedures involving human subjects were approved by the Ethics Commission of Tehran University of Medical Sciences (IR.TUMS.VCR.REC.1395.1597), and all participants signed written informed consent.

\section{Consent for publication}

This is formally to submit the article entitled "The association between deficiency of nutrient on resting metabolic rate in overweight and obese women: a cross-sectional study" prepared by the Tehran University of Medical Sciences for review and, hopefully, publication in your prestigious journal. The authors would like to advise that all authors listed have contributed to the work. All authors have agreed to submit the manuscript to Diabetology \& Metabolic Syndrome. No part of the work has been published before. There is no conflict of interest in this paper.

\section{Availability of data and materials}

Participants in this study did not agree to the public sharing of their data so supporting data is not available.

\section{Competing interests}

All authors declared that they have no competing interests

\section{Funding}

This study is funded by grants from the Tehran University of Medical Sciences (TUMS). (Grant ID: 97-03-161-41155).

\section{Author's contributions}

SFS, AM, AA, and FSh wrote the Manuscript, KhM had full access to all the data in the study and was responsible for the integrity and accuracy of the data. All authors have read and approved the final manuscript.

\section{Acknowledgment}

We are extremely grateful to all the participants who took part in this study and the school of Nutritional and Dietetics at Tehran University of medical sciences.

\section{Sources of Support}

Tehran University of Medical Sciences

\section{Conflicts of Interest}

None 


\section{References}

1. Conklin Al, Ponce NA, Crespi CM, Frank J, Nandi A, Heymann J. Economic policy and the double burden of malnutrition: cross-national longitudinal analysis of minimum wage and women's underweight and obesity. Public Health Nutr. 2018;21(5):940-7.

2. WHO. Eastern Mediterranean Region: Framework for health information systems and core indicators for monitoring health situation and health system performance-2015. From: applications emro who int/dsaf/EMROPUB_2015_EN_1904 pdf. 2015.

3. Jafari-Adli S, Jouyandeh Z, Qorbani M, Soroush A, Larijani B, Hasani-Ranjbar S. Prevalence of obesity and overweight in adults and children in Iran; a systematic review. Journal of Diabetes \& Metabolic Disorders. 2014;13(1):1.

4. Barak F, Falahi E, Keshteli AH, Yazdannik A, Esmaillzadeh A. Adherence to the Dietary Approaches to Stop Hypertension (DASH) diet in relation to obesity among Iranian female nurses. Public health nutrition. 2015;18(4):705-12.

5. Fukunaka A, Fujitani Y. Role of Zinc Homeostasis in the Pathogenesis of Diabetes and Obesity. Int J Mol Sci. 2018;19(2).

6. Shi Z, Makrides M, Zhou SJ. Dietary patterns and obesity in preschool children in Australia: a cross-sectional study. Asia Pac J Clin Nutr. 2018;27(2):406-12.

7. Kim DK. Accuracy of predicted resting metabolic rate and relationship between resting metabolic rate and cardiorespiratory fitness in obese men. Journal of exercise nutrition \& biochemistry. 2014;18(1):25.

8. Buscemi S, Verga S, Caimi G, Cerasola G. Low relative resting metabolic rate and body weight gain in adult Caucasian Italians. International journal of obesity. 2005;29(3):287-91.

9. Ruiz LD, Zuelch ML, Dimitratos SM, Scherr RE. Adolescent Obesity: Diet Quality, Psychosocial Health, and Cardiometabolic Risk Factors. Nutrients. 2019;12(1):43.

10. Bettermann EL, Hartman TJ, Easley KA, Ferranti EP, Jones DP, Quyyumi AA, et al. Higher mediterranean diet quality scores and lower body mass index are associated with a less-oxidized plasma glutathione and cysteine redox status in adults. The Journal of nutrition. 2018;148(2):245-53.

11. Hosseini B, Saedisomeolia A, Allman-Farinelli M. Association Between Antioxidant Intake/Status and Obesity: a Systematic Review of Observational Studies. Biol Trace Elem Res. 2017;175(2):287-97.

12. Thomas-Valdés S, Tostes MdGV, Anunciação PC, da Silva BP, Sant'Ana HMP. Association between vitamin deficiency and metabolic disorders related to obesity. Critical Reviews in Food Science and Nutrition. 2017;57(15):3332-43.

13. Hasan M, Sutradhar I, Shahabuddin A, Sarker M. Double Burden of Malnutrition among Bangladeshi Women: A Literature Review. Cureus. 2017;9(12).

14. Sekiyama M, Jiang HW, Gunawan B, Dewanti L, Honda R, Shimizu-Furusawa H, et al. Double Burden of Malnutrition in Rural West Java: HouseholdLevel Analysis for Father-Child and Mother-Child Pairs and the Association with Dietary Intake. Nutrients. 2015;7(10):8376-91.

15. Fallaize R, Livingstone KM, Celis-Morales C, Macready AL, San-Cristobal R, Navas-Carretero S, et al. Association between diet-quality scores, adiposity, total cholesterol and markers of nutritional status in european adults: Findings from the Food4Me study. Nutrients. 2018;10(1):49.

16. Hu FB. Dietary pattern analysis: a new direction in nutritional epidemiology. Current opinion in lipidology. 2002;13(1):3-9.

17. Md G, Pac A, KüÇüKbay F, Tayfun M, GüL A. Serum zinc, copper, and magnesium levels in obese children. Pediatrics International. 2011;39:339-41.

18. Bertoli S, Leone A, Vignati L, Bedogni G, Martínez-González MÁ, Bes-Rastrollo M, et al. Adherence to the Mediterranean diet is inversely associated with visceral abdominal tissue in Caucasian subjects. Clinical nutrition. 2015;34(6):1266-72.

19. Matthews DR, Hosker JP, Rudenski AS, Naylor BA, Treacher DF, Turner RC. Homeostasis model assessment: insulin resistance and beta-cell function from fasting plasma glucose and insulin concentrations in man. Diabetologia. 1985;28(7):412-9.

20. Katz A, Nambi SS, Mather K, Baron AD, Follmann DA, Sullivan G, et al. Quantitative insulin sensitivity check index: a simple, accurate method for assessing insulin sensitivity in humans. J Clin Endocrinol Metab. 2000;85(7):2402-10.

21. Mirmiran P, Hosseini Esfahani F, Azizi F. Relative validity and reliability of the food frequency questionnaire used to assess nutrient intake: Tehran Lipid and Glucose Study. Iranian Journal of Diabetes and Lipid Disorders. 2009;9(2):185-97.

22. Morgan KJ, Zabik ME, Stampley GL. The role of breakfast in diet adequacy of the US adult population. J Am Coll Nutr. 1986;5(6):551-63.

23. L.K. Mahan SE-s. Krause's food nutrition and diet therapy (10th ed.). WB Saunders, Philadelphia. 2008.

24. Maxwell C, Volpe SL. Effect of zinc supplementation on thyroid hormone function. A case study of two college females. Ann Nutr Metab. 2007;51(2):188-94.

25. Chen M-D, Lin P-Y, Sheu WH-H. Zinc status in plasma of obese individuals during glucose administration. Biological trace element research. 1997;60(12):123-9.

26. Weisstaub G, Hertrampf E, De Romana DL, Salazar G, Bugueño C, Castillo-Duran C. Plasma zinc concentration, body composition and physical activity in obese preschool children. Biological trace element research. 2007;118(2):167-74.

27. do Nascimento Marreiro D, Fisberg M, Cozzolino SMF. Zinc nutritional status and its relationships with hyperinsulinemia in obese children and adolescents. Biological trace element research. 2004;100(2):137-49.

28. Mahawar KK, Bhasker AG, Bindal V, Graham Y, Dudeja U, Lakdawala M, et al. Zinc Deficiency after Gastric Bypass for Morbid Obesity: a Systematic Review. Obes Surg. 2017;27(2):522-9.

29. Alawad AO, Merghani TH, Ballal MA. Resting metabolic rate in obese diabetic and obese non-diabetic subjects and its relation to glycaemic control. BMC Res Notes. 2013;6(382):1756-0500. 
30. Sun MX, Zhao S, Mao H, Wang ZJ, Zhang XY, Yi L. Increased BMR in overweight and obese patients with type 2 diabetes may result from an increased fat-free mass. J Huazhong Univ Sci Technolog Med Sci. 2016;36(1):59-63.

31. Drabsch T, Holzapfel C, Stecher L, Petzold J, Skurk T, Hauner H. Associations Between C-Reactive Protein, Insulin Sensitivity, and Resting Metabolic Rate in Adults: A Mediator Analysis. Front Endocrinol. 2018;9(556).

32. Velthuis-te Wierik EJ, van Leeuwen RE, Hendriks HF, Verhagen H, Loft S, Poulsen HE, et al. Short-term moderate energy restriction does not affect indicators of oxidative stress and genotoxicity in humans. J Nutr. 1995;125(10):2631-9.

33. Owu DU, Antai AB, Udofia KH, Obembe AO, Obasi KO, Eteng MU. Vitamin C improves basal metabolic rate and lipid profile in alloxan-induced diabetes mellitus in rats. J Biosci. 2006;31(5):575-9.

34. Stenzel AP, Carvalho R, Jesus P, Bull A, Pereira S, Saboya C, et al. Serum Antioxidant Associations with Metabolic Characteristics in Metabolically Healthy and Unhealthy Adolescents with Severe Obesity: An Observational Study. Nutrients. 2018;10(2).

35. Park B, Kim J. Oral contraceptive use, micronutrient deficiency, and obesity among premenopausal females in Korea: The necessity of dietary supplements and food intake improvement. PloS one. 2016;11(6):e0158177.

36. Mazur-Bialy Al, Pochec E. Vitamin B2 deficiency enhances the pro-inflammatory activity of adipocyte, consequences for insulin resistance and metabolic syndrome development. Life Sci. 2017;178:9-16. 